\title{
Anal Intraepithelial Neoplasia
}

National Cancer Institute

\section{Source}

National Cancer Institute. Anal Intraepithelial Neoplasia. NCI Thesaurus. Code C4595.

A precancerous neoplastic intraepithelial process involving either the squamous and transitional zones of the anal canal or the perianal skin (anal marg in). 